\title{
Vaccine development and delivery strategies - A glimpse
}

\author{
Rashmi $\mathrm{P}^{1 *}$ and Madhavi BLR ${ }^{2}$ \\ ${ }^{1}$ Associate Professor, Department of Quality Assurance, Acharya \& BM Reddy College of Pharmacy, \\ Bengaluru, India \\ ${ }^{2}$ Assistant Professor, Department of Pharmaceutics, Acharya \& BM Reddy College of Pharmacy, \\ Bengaluru, India
}

Received: 11 February, 2021
Accepted: 19 February, 2021

Published: 20 February, 2021

*Corresponding author: Dr. Rashmi P, Associate Professor, Department of Quality Assurance, Acharya \& BM Reddy College of Pharmacy, Bengaluru, India, Tel: +919886946637; E-mail: dr.rashmip@acharya.ac.in; rshvsh@gmail.com

ORCID: https://orcid.org/0000-0002-0392-2284

Keywords: Vaccine; Epitope; Mucosal vaccine;

Thermostable vaccine; Immunoinformatics

https://www.peertechzpublications.com

Check for updates

\begin{abstract}
Vaccines are one of the oldest biological products which are most successful in modulating immune response against various life-threatening infectious diseases. Currently, there are many advancements in the designing and delivery of vaccines. Starting from the use of live attenuated and dead microbes as vaccines, to the stage of mapping antibodies using various software and algorithms for designing desired vaccine, the journey has taken many turns in the last two centuries. Current write up gives a glimpse of various developments in the development of vaccines as well as delivery strategies like use of immunoinformatics, artificial intelligence and efforts made towards the delivery of vaccines using nanoparticles, vectors, hydrogels as adjuancts.
\end{abstract}

\section{Introduction}

Vaccines are the biological products used to provide active immunity to infectious diseases. It is a well-known fact that generally vaccines are made either of killed or attenuated microbes, toxoids, virulent protein subunits, or polysaccharide outer coats along with proteins or toxins. The history of vaccines dates back to 1798 when Edward Jenner gave smallpox exudates to an 8-year-old boy who did not get smallpox after being infected [1]. Since then, research on vaccines underwent technological as well as medical changes, and several vaccines, as well as antitoxins for diseases like diphtheria, tetanus, plague, smallpox, rabies, cholera, were developed by the mid of $20^{\text {th }}$ century. Mass vaccination was introduced by the World Health Organization (WHO) for smallpox and its success prompted many regulatory agencies to make guidance and regulations for the discovery, production, and usage of vaccines.Thereby sales of viruses, serums, toxins, and related products were brought under regulations in the $20^{\text {th }}$ century [2]. During that period when vaccines were made available, highincome countries began recommending routine vaccination for children. Currently, in most countries, vaccination is mandatory for children. The widespread success of vaccination proved that vaccines are lifesaving interventions. This paper tries to shed light on few developments in vaccine development and delivery technologies.

\section{Advancements in vaccine technology}

Across decades, with occurrence of newer diseases infectious / non-infectious / allergic there is a constant need for better therapeutic and treatment options. Prevention of the occurrence of the disease is a desirable option. Secondly, with the global population explosion, the preventive therapy calls for large scale production of the therapeutic agent. Thus vaccine research has been a thrust area. Extensive studies have been undertaken in the areas of candidates for vaccine development as well as novel methods for vaccine delivery.

\section{Immunogen source - advancements}

Live or attenuated vaccines are considered first and secondgeneration vaccines respectively. Vaccines comprising DNA plasmids that are capable to express major pathogenic protein sequences in the host are considered third-generation vaccines [3] Though DNA vaccines were found to deliver outstanding immunogenicity with the capacity to be in the host cell for months together, there were concerns of developing tolerance and autoimmune reactions which required an extensive study to prove either way. To prove the strategy as effective it required a clinical trial with a huge number of human volunteers which is an actual risk. Thereby nowadays, the focus shifted to other strategies to discover and develop vaccines [4]. A recent 
phase in the advancement of vaccines is the research in the field of epitope vaccines. The parts of amino acid sequences of whole antigens that are responsible for the stimulation of immunogenic responses are known as epitopes or antigenic determinants. Generally, the epitopes are recognized from antibodies, B cells, and $\mathrm{T}$ cells. Accurate knowledge of immunogenic protein is required for the development of epitope vaccine. The reverse vaccinology approach was used to derive the information of the codon sequence of the DNA for the development of complementary DNA and further, it will be translated into the protein sequence of the respective protein [5].

\section{Immunoinformatics}

With theacquaintance of the primary sequence of antigenic protein, and determining immunogenicity experimentally by using smaller parts of the proteins on animals epitopes can be recognized. As this work is more tedious and expensive, in silico prediction programs can be used. This approach led to the development of a new field called immunoinformatics, which involves the analysis of immunological data using various algorithmic models. Various approaches of immunoinformatics are sequence-based methods and structure-based approaches. The first one comprises of various methods like Motif searchbased approach, prediction by the artificial neural network, prediction by the support vector machine, Hidden Markov models, prediction by quantitative matrices driven methods involving quantum mechanics. Sequence-based approaches cover docking of peptides and screening of peptide libraries, application of threading algorithms, binding energy, and molecular dynamics [6]. In contrast to the above, the development of $\mathrm{B}$ cell epitopes is more challenging because they are discontinuous and are constitutedby amino acid residues that are positioned in diverse regions of the protein and quaternary/tertiary structure of protein formed due to folding forms a region called as epitope. These amino acid groups cannot be isolated as such in the form of an antigen. Hence, Structural Based Reverse Vaccinology (SBRV) which focuses on the use of a monoclonal antibody against the protein antigen to mimic the structure is used for development of epitope vaccine. As part of this, many scientists tried to use machine learning and this strategy was not that successful [5].

\section{Immunotherapy}

Vaccines in general modulate immune response. This principle of modulating the body's immune system has been extended towards the therapy of non -infective clinical indicationsand is called immunotherapy. In Immunotherapy or biological therapy, the immune system is either activated or suppressed andrespectively termed as activation immunotherapy and suppression immunotherapy. Cancer immunotherapy and allergen immunotherapy are being widely researched. Immunotherapy has various approaches based on the biological entity being employed e.g. interleukins, cytokines, chemokines, etc. Allergen immunotherapy involves repeated administration of allergens to allergic individuals over a long period to confer long-term relief of symptoms and improvement in the quality of life during subsequent natural allergen exposure [7]. In immunotherapy of cancer, the host's immune response is activated. It considers the activation of host's suppressor mechanisms by modulating checkpoints. It also efforts towards increasing the effector cell number and the production of soluble mediators [8].

\section{Artificial intelligence for vaccine development}

Artificial Intelligence (AI) tools have penetrated all realms of scientific research. For vaccine development to AI is being applied. The Human Immunomics Initiative (HII) project from the Harvard T.H. Chan School of Public Health and the Human Vaccines Project together are designing the AI platform for capturing data about the method to generate an immunogenic response and for predicting the responses of the population who are expected to be vaccinated for a range of diseases [9]. Currently, AI is being applied to develop the vaccine for Covid-19. As per the report, development of a computer model that could screen and eliminate $95 \%$ of potential candidates and arrive at choices to construct a multi-epitope vaccine, which can attack the spike proteins of coronavirus [10].

\section{Veterinary vaccines}

Vaccination for animals is an equally growing area of work especially for the case of zoonoses to prevent harm to humans from infections originating in animals. Viral disease - the SARS-CoV and MERS-CoV have been reported to have originated in bats. It was concluded from studies that SARSCoV had spread from infected civets to people, while MERS$\mathrm{CoV}$ spreads from infected dromedary camels to humans [11]. Regarding SARS- CoV-2, the latest information directs towards bats being a source of infection [12]. Poultry, cattle, horse, dogs, and cats are a few animals to mention where vaccination is a concern and research advancement is a continued need.

\section{Vaccination delivery advancements}

Most of current vaccines are delivered in the form of injection. Injectable vaccines are well established for desired therapeutic outcome and their production facility is geared up to meet global demand. Yet, modes of alternate delivery are desirable to avoid the inconvenience associated with injections. Oral vaccines are commercially available and the oral polio vaccine being the most popular. Oral vaccines are also preferred for immunization for the wildlife population for dreadful diseases such as rabies. Some commercial oral vaccines include LUIVAC (respiratory infection), Vaxchora (cholera), Vivotif, (typhoid), RABORAL V-RG (rabies), Dukoral (Cholera, diarrhea), Tetramune, Rotateq, Rotashield, (Rotavirus), Biostim (Klebsiella) [13].

\section{Mucosal vaccination and vaccine formulations}

Pathogens gain access to the body via mucosal sites which is the first line of defence for the body. Mucosal vaccination is an upcoming area for generating protective immunity at mucosal sites and countering pathogen invasion and dissemination. The routes forthe mucosal vaccine are predominantly oral and nasal administration while vaginal, rectal, ocular, and sublingual routes are less popular. The antigenic protein 
may be isolated from the infective microbe and formulated for delivery. Reports on mucosal vaccination either as microparticles(PLG particles loaded with ova albumin [14]), nanoparticles (plasmid DNA loaded chitosan nanoparticles for nasal delivery [15]) liposomes(mannose-PEG-cholesterol (MPC)/lipid A-liposomes (MLLs) entrapping model antigen Bovine Serum Albumin (BSA) [16], etc.

\section{Biological carriers for vaccines}

Bacteria- Gram-negative (E .coli and S. Typhimurium as attenuated organisms) and gram-positive bacteria (Lactococcus, Streptococcus, and Lactobacillus) have been used for the vaccine of plasmid DNA as theimmunogenin poultry for mucosal vaccine delivery [17]. Virosomes are another class of carrier system. They are not the virus but are they are unilamellarlipid membrane vesicles made of viral membrane protein and devoid of viral genetic material. The antigenic material is encapsulated in the vesicle for delivery [18].

\section{Plant-based edible vaccines}

This vaccination strategy adds to the mucosal vaccination domain of conferring immunity in addition to systemic immunity. Plant-based vaccine development has also been termed molecular farming since the required biopharmaceutical molecules are obtained from genetically engineered plants. The antigenic moiety is protected within the plant cell and need not be specifically harvested and purified. Lettuce leaves containing soluble antigen of Bacillus anthracis were developed. These were reported to be stable at room temperature. The antigen did not degrade. Other plants include tomato, papaya, and carrot. The article also reports the use of insects and yeast as source delivery tools for vaccines. The products are in the pathway of clinical trials phase 1 or phase 2 [19].

\section{Sublingual immunotherapy(SLIT)}

Allergen immunotherapy has so far been carried out by Subcutaneous (SC) injections. The SC therapy was not favorable since there were fatalities reported. SLIT ispromising especiallyfor allergic rhinitis and asthma [20]. SLIT may be delivered as a tablet, film/strip, or as drops [21].

\section{Other formulation strategies for vaccine delivery}

In addition to the above advancements in vaccine delivery, other formulation strategies for vaccines include micellar delivery systems, polymeric nanoparticles, dendrimer based delivery, needle-free delivery, microneedle system for vaccines [18].

\section{Thermostable vaccines- spray drying and other ap- proaches}

Spray drying technology has been tailored to meetthe requirements of the vaccine industry. Manyvaccines are unstable as liquids or need to be processed by a cold chain management system. A feasible alternate is provided by developing heatstable vaccines. Virosomes have been processed by spray drying [22]. Similarly for tuberculosis lyophilization of oil-in- water nano emulsion adjuvants has been worked upon to yield stable product [23]. Human papillomavirus capsomere has been delivered as heat-stable microparticles. Glass-forming polymers and trehalose are the first spray-dried antigen/ adjuvant formulations to form glassy microparticles. Atomic Layer Deposition (ALD) reactions conducted in fluidized beds are then used to coat the microparticles with defined numbers of molecular layers of alumina that modulate the timed release of the internalized antigen and act as adjuvants [24]. Microneedle array patch technology has been developed for Hepatitis B surface Antigen (HBsAg) employing hydroxyethyl starch (HES) and Chondroitin Sulfate (CS) and saponin QS-21 as an adjuvant, both incorporated in HES-based MNAP [25]

\section{Adjuvant advancements in vaccine development}

Adjuvants are substances used to potentiate the immunogenic effect of the vaccine. They also serve other purposes. Different kinds of adjuvants are being looked into for conferring better safety, stability, and efficacy of the antigen. Aluminum hydroxide is a popular adjuvant. It has been reported to protect antigens from degradation [26]. Protein-based adjuvants are potential candidates. Heat-labile toxin produced by the double-mutant $E$. coli is a novel protein adjuvant that is in the preclinical stage with various vaccine candidates [27]. Another protein-based adjuvant reported for mucosal vaccination is Unlipidated outer membrane protein 19 (U-Omp19) can be used in vaccine formulations. U-Omp19 is reported to be able to inhibit gastrointestinal and lysosomal peptidases, and prevent digestion of antigenic protein and enhance their availability to the antigen presenting cells in vivo [28]. Polymeric Systems is another area to explore as a vaccine adjuvant. Biodegradable polyanhydrides have been reported to optimally achieve many parameters like enhancing antigenic response, induce immunologic memory, provide better patient acceptance, reduce inflammation, and be stable in challenging environments and thus support the global market [29]. Genetic molecular adjuvants are used to potentiate the response to DNA vaccines. Various plasmids like cytokine encoded, chemokine encoded, co-stimulatory molecule encoded plasmids, and plasmids encoding pathogenRecognition Receptor (PRR) Ligands and Immune-Signaling Molecules are certain molecular adjuvants [30].

\section{Future prospects}

Nowadays, nucleic acid vaccines are becoming more promising as they are able to elicit both cell mediated as well as humoral immunity. An effort has been done for the use of nanoparticles for nucleic acid vaccine delivery to overcome the action of endonucleases on vaccines when given in injection form. Use of liposomal nanoparticles, polymeric nanoparticle system, natural polymers, inorganic nanoparticles, peptide based nanoparticles was done to deliver nucleic acid vaccines and many formulations are in different phases of clinical trials [31]. Attempts were done for topical delivery of vaccines through the use of star shaped, milli meter scaled, made of aluminium oxide or stainless steel possessing micron scale projections which are able to make pores across stratum corneum. Though, it was not successful as expected, and most challenge, this 
new technology require further research to use in its fullest potential [32]. Even various vectors like, influenza A virus vector, Venezuelan Equine Encephalitis (VEE) virus vector, adenovirus-based vectors, lactic acid bacterial vectors were tried to deliver vaccines against botulism, but needs further optimization [33]. Orotransmucosal delivery of vaccines using various hydrogels in different composition accompanied with various artificial intelligence tools [34].

The advancements in vaccine technology both in the candidates suitable for generating an immunogenic response as well as in delivery of the vaccine mentioned are potential areas for exploration and commercialization. In the current wake of Covid-19 there has been global uproar in vaccine research, clinical trials, approval, large scale manufacturing, cold chain management and mass vaccination schemes. The possible mutations and the efficacy of the vaccines on the new strains is debatable. Thus if the existing AI tools may be used to predict possible mutations in the microbes/virus there would be better chance to design and develop better vaccines. Similarly AI can be used with the VARES - vaccine adverse event report system to work towards selecting population to whom vaccine should not be administered and thus may be avoid fatalities.

\section{Conclusion}

In the present-day situation, vaccines are the most useful biological products for the treatment of various infectious disorders. The efficacy, specificity and ability of vaccines to alter immune response has made them to be in prime focus because more active immune response against any particular disease is more effective than the small molecules which are not free from side effects. Era of artificial intelligence has prompted scientist to gather and analyse the available data for the use of vaccine development. Though technological advancements intervened in the vaccine development, attempts are made to improve formulation and vaccine delivery methodologies, to overcome the limitations of efficacy, selectivity and ability to stimulate immune response. In summary, vaccine designing, development, formulation and delivery need to go hand in hand to reap the advantage of vaccines so that mankind will get its advantage in its fullest form.

\section{References}

1. Lahariya C (2016) Vaccine epidemiology: A review. J Family Med Prim Care 5: 7-15. Link: https://bit.ly/2Nlezkj

2. Vaccine history 2021. Link: https://bit.ly/2M4Unmn

3. Palatnik-de-Sousa CB, Soares IS, Rosa DS (2018) Editorial: Epitope Discovery and Synthetic Vaccine Design. Front Immunol 9: 826. Link: https://bit.ly/3pw6XbP

4. Klinman DM, Takeno M, Ichino M, Gu M, Yamshchikov G, et al. (1997) DNA vaccines: safety and efficacy issues. Springer Semin Immunopathol 19: 245256. Link: https://bit.ly/3azj3N8

5. Palatnik-de-Sousa CB, Soares IS, Rosa DS (2018) Editorial: Epitope Discovery and Synthetic Vaccine Design. Front Immunol 9: 826. Link: https://bit.ly/3pw6XbP

6. Patronov A, Doytchinova I (2013) T-cell epitope vaccine design by immunoinformatics. Open Biol 3: 120139. Link: https://bit.ly/2NGOY6W
7. Canonica GW, Durham SR(2016) Allergen Immunotherapy for allergic rhinitis and asthma: A Synopsis. Link: https://bit.ly/3s7boeR

8. Stanculeanu DL, Daniela Z, Lazescu A, Bunghez R, Anghel R (2016) Development of new immunotherapy treatments in different cancer types. $J$ Med Life 9: 240-248. Link: https://bit.ly/3dqXPD9

9. New Initiative Uses Artificial Intelligence for Vaccine Development 2021. Link: https://bit.ly/3k46Uml

10. Artificial intelligence yields new ways to combact the coronavirus 2021. Link: https://bit.ly/2NFPY9W

11. COVID-19, MERS \& SARS 2021. Link: https://bit.ly/3pAd2ny

12. Wuhan scientists admit to being bitten by COVID-19 infected bats 2021. Link: https://bit.ly/2ZuiDBp

13. Oral Vaccines Market 2021. Link: https://bit.ly/3ay5u0x

14. Delgado A, Lavelle EC, Hartshorne M, Davis SS (1999) PLG microparticles stabilised using enteric coating polymers as oral vaccine delivery systems. Vaccines 17: 2927-2938. Link: https://bit.ly/3s6CPFF

15. Khatri K, Goyal AK, Gupta PN, Mishra N, Vyas SP (2008) Plasmid DNA loaded chitosan nanoparticles for nasal mucosal immunization against hepatitis $\mathrm{B}$. Int J Pharm 354: 235-241. Link: https://bit.ly/3k4BtIA

16. Zhena Y, Wang N, Gao Z, Maa X, Wei B, et al. (2015) Multifunctiona liposomes constituting microneedles induced robust systemic and mucosal immunoresponses against the loaded antigens via oral mucosal vaccination. Vaccines 33: 4330-4340. Link: https://bit.ly/3pC6ipg

17. Jazayeri SD, Poh CL (2019) Recent advances in delivery of veterinary DNA vaccines against avian pathogens. Vet Res 50: 78. Link: https://bit.ly/3k2bDF8

18. Saroja C, Lakshmi PK, Bhaskaran S (2011) Recent trends in vaccine delivery systems: A Review. Int J PharmInvest 1. Link: https://bit.ly/3k0Kxyi

19. Criscuolo E, Caputo V, Diotti RA, Sautto GA, Kirchenbaum GA, et al. (2019) Alternative methods of vaccine delivery: An overview of edible and intradermal vaccines. J Immun Res 1-13 Link: https://bit.ly/3qyOQn7

20. Passalacqua G, Canonica GW, Bagnasco D (2016) Benefit of SLIT and SCIT for Allergic Rhinitis and Asthma. Curr Allergy Asthma Rep 16: 88. Link: https://bit.ly/3qDi2JI

21. Sublingual Immunotherapy 2021. Link: https://bit.ly/37uCSDn

22. Amacker M, Smardon C, Mason L, Sorrell J, Jeffery K, et al. (2020) New GMP manufacturing processes to obtain thermostable HIV-1 gp41 virosomes under solid forms for various mucosal vaccination routes. npj Vaccines 5: 41. Link: Link: https://bit.ly/3dq8hKS

23. Kramer RM, Archer MC, Orr MT, Dubois Cauwelaert N, Beebe EA, et al. (2018) Development of a thermostable nanoemulsion adjuvanted vaccine against tuberculosis using a design-of-experiments approach. Int J Nanomedicine 13 3689-3711. Link: https://bit.ly/2M2RK4j

24. Garcea RL, Meinerz NM, Dong M, Funke H, Ghazvini S, et al. (2020) Singleadministration, thermostable human papillomavirus vaccines prepared with atomic layer deposition technology. npj Vaccines. 5: 45. Link: https://bit.ly/3k2zQv6

25. Poirier D, Renaud F, Dewar V, Strodiot L, Wauters F, et al. (2017) Hepatitis $B$ surface antigen incorporated in dissolvable microneedle array patch is antigenic and thermostable. Biomaterials 145: 256-265. Link: https://bit.ly/2NcknNi

26. Colaprico A, Senesi S, Ferlicca F, Brunelli B, Ugozzoli M, et al. (2020) Adsorption onto aluminum hydroxide adjuvant protects antigens from degradation. Vaccine 38: 3600-3609. Link: https://bit.ly/3qAeSX3

Citation: Rashmi P, Madhavi BLR (2021) Vaccine development and delivery strategies-A glimpse. J Vaccines Immunol 7(1): 004-008. 
27. Toprani VM, Hickey JM, Sahni N, Toth RT, Robertson GA, et al. (2017) Structural Characterization and Physicochemical Stability Profile of a Double Mutant Heat Labile Toxin Protein Based Adjuvant. J Pharm Sci 106: 3474-3485. Link: https://bit.ly/3pAkijx

28. Darriba LM, Cerutti ML, Bruno L, Cassataro J, Pasquevich KA (2021) Stability Studies of the Vaccine Adjuvant U-Omp19. J Pharm Sci 110: 707-718. Link: https://bit.ly/37q4Gcc

29. Kelly SM, Mitra A, Mathur S, Narasimhan B (2019) Synthesis and characterization of rapidly degrading polyanhydrides as vaccine adjuvants. Biomat Sci Eng 6: 265-276 Link: https://bit.ly/3ufo70T

30. Sabbaghi A, Ghaemi A (2021) Molecular Adjuvants for DNA Vaccines: Application, Design, Preparation, and Formulation. Methods Mol Biol 2197: 87 112. Link: https://bit.ly/3duNhCO
31. Lahariya C (2016) Vaccine epidemiology: A review. J Family Med Prim Care 5 7-15. Link: https://bit.ly/3pwHVJO

32. Tadros AR, Romanyuk A, Miller IC, Santiago A, Noel RK, et al. (2020) STAR particles for enhanced topical drug and vaccine delivery. Nature Medicine 26 341-347. Link: https://go.nature.com/3bnOs4e

33. Yan $Y$, Diaz-Arévalo D, Wang $H$, Chen $Y$, Zeng M (2020) Vaccine delivery strategies against botulism. Drug Delivery Aspects 191-209. Link: https://bit.ly/3bk9rVF

34. Garcia-del Rio L, Diaz-Rodriguez P, Landin M (2021) Design of novel orotransmucosal vaccine-delivery platforms using artificial intelligence. European Journal of Pharmaceutics and Biopharmaceutics 159: 36-43. Link: https://bit.ly/37qE2zl

\section{Discover a bigger Impact and Visibility of your article publication with}

\section{Peertechz Publications}

\section{Highlights}

* Signatory publisher of ORCID

* Signatory Publisher of DORA (San Francisco Declaration on Research Assessment)

* Articles archived in worlds' renowned service providers such as Portico, CNKI, AGRIS, TDNet, Base (Bielefeld University Library), CrossRef, Scilit, J-Gate etc.

* Journals indexed in ICMJE, SHERPA/ROMEO, Google Scholar etc.

- OAI-PMH (Open Archives Initiative Protocol for Metadata Harvesting)

* Dedicated Editorial Board for every journal

* Accurate and rapid peer-review process

* Increased citations of published articles through promotions

* Reduced timeline for article publication

Submit your articles and experience a new surge in publication services (https://www.peertechz.com/submission).

Peertechz journals wishes everlasting success in your every endeavours.

Copyright: @ 2021 Rashmi P, et al. This is an open-access article distributed under the terms of the Creative Commons Attribution License, which permits unrestricted use distribution, and reproduction in any medium, provided the original author and source are credited. 